\title{
Congenital dyserythropoietic anaemia with unusual cytoplasmic inclusions
}

\author{
M. W. KENNY, R. M. IBBOTSON, M. J. HAND, AND M. J. TECTOR \\ From the Department of Haematology, North Staffs Hospital Centre, Hartshill Road, Hartshill, \\ Stoke-on-Trent ST4 7PX, UK
}

SUMMARY A case of congenital dyserythropoietic anaemia is described which appears to be at variance with the accepted classification. The morphological findings are of normoblastic hyperplasia with marked cytoplasmic vacuolation. Electron microscopy shows these to be myelin figures in all stages of erythroid differentiation.

Dyserythropoiesis occurs in a variety of congenital and acquired haematological disorders and is recognised by morphological and ultrastructural features, with ineffective erythropoiesis. A group of congenital dyserythropoietic anaemias has been recognised and subsequently classified (Heimpel and Wendt, 1968). The present report describes a case with mild clinical features, associated with unusual cytoplasmic inclusions, which cannot be ascribed to any of the classical types.

\section{Case report}

A 58-year-old Caucasian man was admitted for arterial surgery with a 12-year history of intermittent claudication. Examination was unremarkable apart from absence of arterial pulses distal to the femoral arteries, and, in particular, there was no lymphadenopathy or hepatosplenomegaly. In 1958 he had been investigated for anaemia; the haemoglobin at that time was $70 \%(10.4 \mathrm{~g} / \mathrm{dl})$ and the blood film showed anisocytosis and poikilocytosis. The spleen was not palpable, and further investigation, viz., osmotic fragility, produced no diagnosis. Bone marrow aspiration was not performed and subsequent haemoglobin estimations ranged from 10.4 to $12 \cdot 3 \mathrm{~g} / \mathrm{dl}$ over the next few years.

Investigations during the present admission were as follows: $\mathrm{Hb} 10 \cdot 1 \mathrm{~g} / \mathrm{dl}, \mathrm{MCV} 87 \mathrm{fl}, \mathrm{MCH} 29.5 \mathrm{pg}$, RBC $3.45 \times 10^{12} / 1$, WBC $7.2 \times 10^{9} / 1$ (normal differential count), platelets $190 \times 10^{9} / 1$, and reticulocytes $1.1 \%$; examination of the peripheral blood showed marked anisocytosis and poikilocytosis. Bilirubin $8 \mu \mathrm{mol} / 1$ (normal 1·7-17.0 $\mu \mathrm{mol} / \mathrm{l}$ ), lactic

Received for publication 10 May 1978 dehydrogenase $153 \mathrm{mU} / \mathrm{ml}$ (normal 60-250 mU/ml), haptoglobins $0.4 \mathrm{~g} / 1$ (normal 0.3-2.0 g/l); no excess urobilinogen present in the urine; serum iron $15 \mu \mathrm{mol} / 1$ (normal 13-32 $\mu \mathrm{mol} / \mathrm{l}$ ), iron binding capacity $52 \mu \mathrm{mol} / 1$ (normal $45-70 \mu \mathrm{mol} / \mathrm{l}$ )l.

Other biochemical tests, including electrolytes, urea, proteins, and serum lipids, were within normal limits: serum B12 $400 \mathrm{pg} / \mathrm{ml}$ (normal 150-800 pg/ml), serum folate $3.0 \mathrm{ng} / \mathrm{ml}$ (normal 3.5-15.0 ng/ml).

Further haematological investigations revealed a normal haemoglobin electrophoretic pattern with no increase in $\mathrm{Hb} \mathrm{A}_{2} 3.2 \%$ (normal 1-3.5\%) and $\mathrm{Hb} \mathrm{F}$ $0.9 \%$ (normal $<1 \%$ ), and glucose-6-phosphate dehydrogenase and pyruvate kinase assays showed no deficiency. Osmotic fragility performed on fresh blood, and after incubation at $37^{\circ} \mathrm{C}$ for 24 hours, produced normal curves, and the autohaemolysis test showed no increased lysis at 48 hours. Ham's acidified-serum lysis test was negative, using a total of 17 different sera, and the sucrose lysis test was also negative. No atypical antibodies were found in the patient's serum, and both $I$ and $i$ antigen status (performed by Dr G. W. Bird, Birmingham Blood Transfusion Service) was normal.

Ferrokinetic studies were performed with ${ }^{59} \mathrm{Fe}$ after four weeks' folic acid therapy and gave the following results: $T \frac{1}{2}$ clearance 46 (normal 60-140) minutes, plasma iron turnover 288 (normal 72-144) $\mu \mathrm{mol} / \mathrm{l} / \mathrm{day}$, and red cell incorporation $38 \%$ at day 10 (normal $70-80 \%$ ). This was interpreted as demonstrating ineffective erythropoiesis.

BONE MARROW

Two bone marrow aspirations were performed, the second after treatment for one month with oral folic acid, $5 \mathrm{mg}$ twice daily; apart from giant metamyelo- 


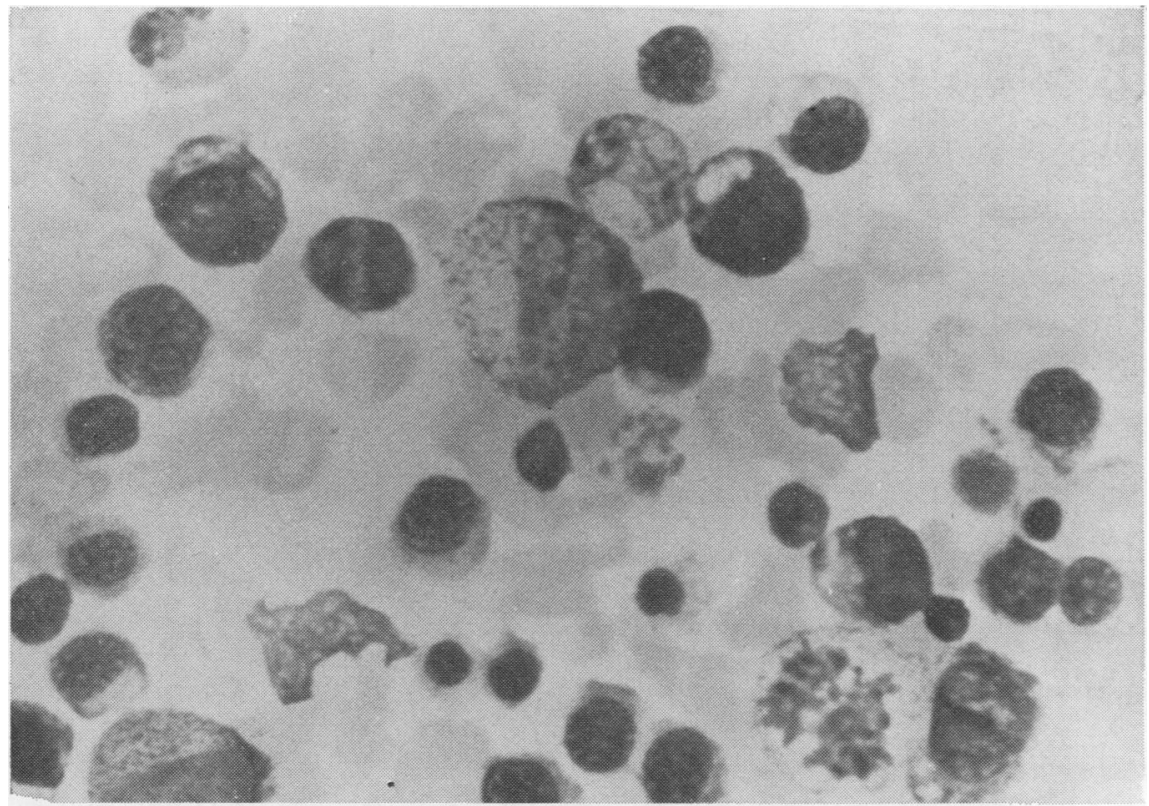

Fig. 1 Normoblasts showing marked cytoplasmic vacuolation (Leishman Giemsa $\times 405)$.

cytes in the pre-treatment specimen, the features were similar. The marrow was hypercellular, with marked erythroid hyperplasia, the myeloid:erythroid ratio being 1:3. Erythropoiesis was normoblastic, with a small proportion of the erythroblasts $(3-4 \%)$ having nuclear budding. Multinuclearity was not a prominent feature, only $2-3 \%$ of all erythroblasts being binucleate, and none having three or more nuclei. Although some erythroid cells were connected by thin strands of cytoplasm, no internuclear bridges were present. The most remarkable feature was the presence in $45-50 \%$ of erythroblasts of marked cytoplasmic vacuolation (Fig. 1), which occurred at all stages of development from proerythroblast to pyknotic erythroblast. The contents of the vacuoles were both periodic acid Schiff (PAS) and Sudan black negative. The white cell series and the megakaryocytes appeared normal. Perl's stain revealed adequate iron stores and no ring sideroblasts.

\section{ELECTRON MICROSCOPY}

The bone marrow was primarily fixed in phosphate buffer $2 \%$ glutaraldehyde followed by secondary fixation in $1 \%$ osmium tetroxide. After embedding in Araldite, ultra-thin sections were cut on an LKB ultratome III and stained with uranyl acetate and Reynolds lead citrate. They were examined on an AEI Corinth 500 electron microscope.

The nuclear structure appeared normal at all stages of maturation, with even condensation of ihe chromatin in the polychromatic and intermediate normoblasts. Nuclear pores were of normal size, and no invasion of the nucleus by cytoplasm or cytoplasmic organelles was seen. In some erythroblasts the nuclear membrane became indistinct for a short distance around the nucleus, but in no place could it be traced to form cisternal structures at the cell periphery. The occasional nucleus had small 'bud'like protrusions, suggesting gross abnormalities of nuclear division, but no chromatin bridges between imperfectly divided cells were demonstrated.

Numerous, large cytoplasmic inclusions were present at all stages of the developing erythroblast and appeared to be the counterpart of the vacuolation noted at light microscopy (Fig. 2). Some of these inclusions had membrane-like structures arranged in concentric patterns simulating myelin figures; others were structureless, composed of amorphous pale material. In several inclusion bodies, a combination of these features was present, with membrane dividing up amorphous material of varying electron density. Occasional degenerating cytoplasmic organelles, such as mitochondria, were also present in these bodies (Fig. 3). Similar appearances were seen in non-nucleated red cells.

\section{Discussion}

Heimpel and Wendt (1968) classified congenital dyserythropoietic anaemia (CDA) into three types 
Fig. 2 Electron micrograph of normoblast containing cytoplasmic autophagic vacuoles $\times 12300$.

according to blood and bone marrow morphology. Type I was characterised by macrocytosis, megaloblastoid changes, and internuclear chromatin bridges; type II with normocytosis, bi- and multinuclearity, pluripolar mitoses, and karyorrhexis; and type III with macrocytosis, multinuclearity with up to 12 nuclei, and gigantoblasts. Type II has also been found to have serological abnormalities of the red cells, demonstrated by increased agglutination by anti-I and anti-i, increased lysis by anti-i, and a positive acidified-serum lysis (Ham's) test; the eponym HEMPAS has been applied to this variety
(Crookston et al., 1969). Several cases with features at variance with these three types have subsequently been described, and they have recently been reviewed (David and van Dorpe, 1977). In addition, dyserythropoietic morphology has been observed in $N$ acquired and other congenital conditions (Lewis and Verwilghen, 1972).

The erythroid hyperplasia in the presence of reticulocytopenia suggests ineffective haemopoiesis, which was confirmed by the iron turnover studies demonstrating red cell iron incorporation of $38 \%$. The possibility of an acquired haemopoietic disorder 


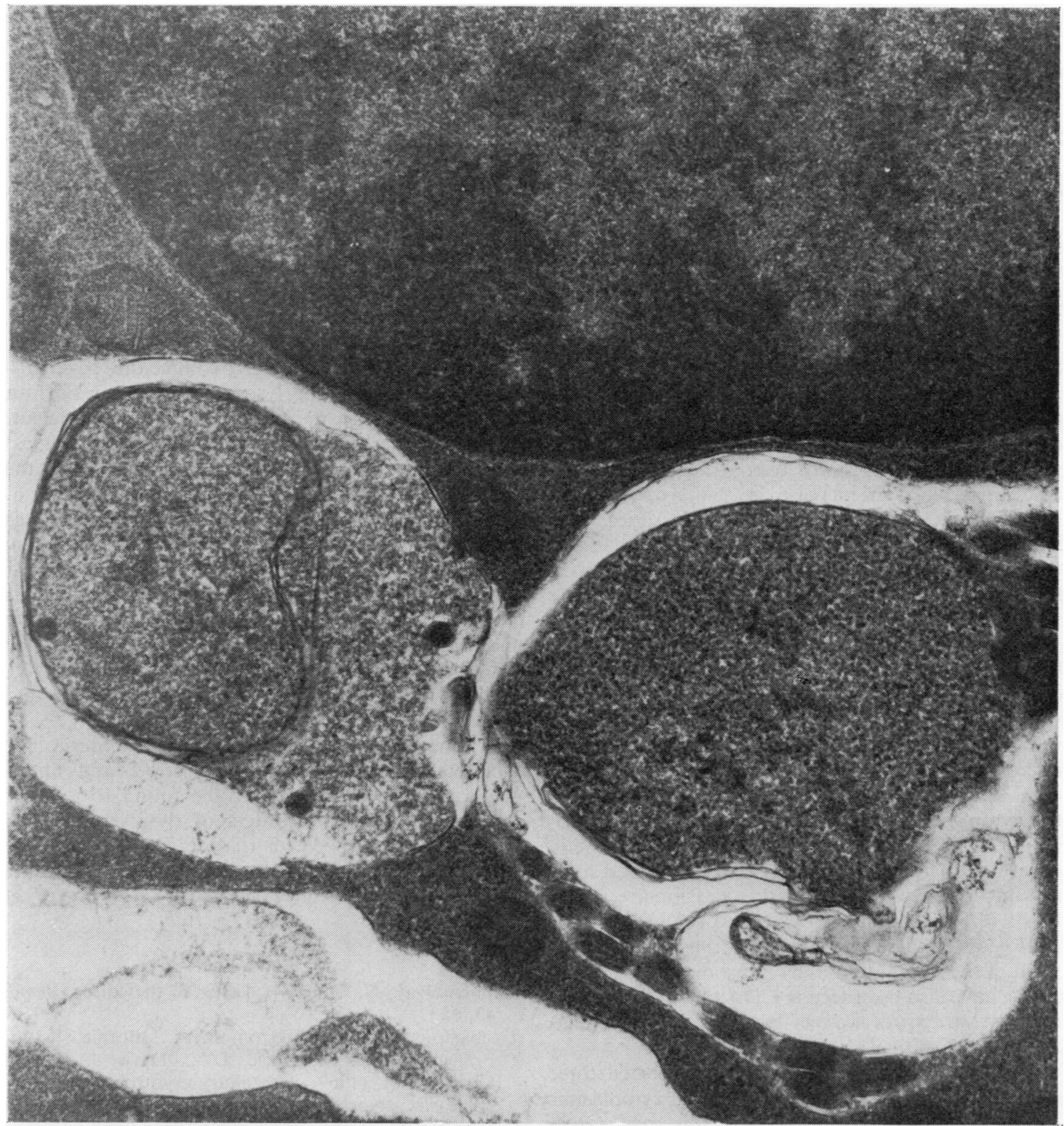

Fig. 3 Electron micrograph of normoblast cytoplasm showing contents of autophagic vacuole and degenerating mitochondria $\times 32000$.

is suggested by the age of this patient, but the investigations for anaemia performed 20 years previously and the absence of abnormalities in the developing granulocytic or megakaryocytic lines argue against this. CDA has also been described in middle-aged and elderly patients (Maldonado and Taswell, 1974; Dvilansky et al., 1974; Bethlenfalvay, 1974).
Detailed descriptions have been made of the morphological and electron microscopic features of CDA type I (Heimpel et al., 1971; Lewis et al., 1972) and type II (Wong et al., 1972; Verwilghen et al., 1973). By comparison the morphological changes of the case described suggest a classification of type II as erythropoiesis is essentially normoblastic. This is not supported by the serological studies, that is, 
negative acidified serum lysis and normal I status. The electron microscope appearance of the erythroblast nuclei shows none of the features that give rise to the megaloblastoid structure seen with the light microscope in type I, namely, uneven chromatin condensation and invasion of the nucleus by cytoplasm. This case cannot therefore be placed in the current classification.

Other patients with features of both types I and II have been described. McBride et al. (1971) reported on two sisters who had negative acidified-serum lysis tests, though the bone marrow was morphologically that of type II, being normoblastic with numerous binucleate cells. Weatherall et al. (1973) and Hruby et al. (1973) have separately described cases with moderate to severe anaemia, normoblastic marrows, and negative acidified-serum lysis tests. They both demonstrated an imbalance of globin chain synthesis, with an excess of $\alpha$-chains over $\beta$-chains. This was associated with an increase in the proportion of haemoglobin $F$ and, in Weatherall's series, also haemoglobin $\mathbf{A}_{2}$. These cases therefore differed from the patient described who had normal levels of haemoglobin $\mathrm{F}$ and $\mathrm{A}_{2}$ and was clinically less severely affected.

A prominent feature of the case described were the cytoplasmic vacuoles present in the developing erythroblasts (Fig. 1). Both PAS and Sudan black stains were negative, suggesting that the contents were not composed of fat or carbohydrate. Electron microscopy demonstrated large inclusion bodies (Fig. 2), which were interpreted as the contents of the cytoplasmic defects. The concentric membranelike structures recall the arrangement of myelin encasing a nerve axon, and have been referred to as myelin figures when present in occasional erythroblasts of patients with CDA type I (Heimpel et al., 1971). Autophagic vacuoles, resulting from engulfment of the myelin figures by lysosomes (Lewis et al., 1972), have also been seen in CDA type I, but neither of these structures was as large or as frequent as those in this patient.

However, Weatherly et al. (1974) reported three members of a family, two of whom had cytoplasmic inclusions similar to that seen in this case. Gross vacuolation was seen with a light microscope, and under the electron microscope inclusion bodies, degenerating mitochondria, and myelin figures were present. 'Necklace-like' bodies were also seen in one family member. Their cytoplasmic abnormalities were not reported as being found in proerythroblasts, and their cases also differed in having multinuclearity in $10-20 \%$ of the developing erythroblasts.

Lewis and Frisch (1976) have associated the abnormalities of dyserythropoiesis with defects of nuclear membrane, and degradation of this structure could account for the myelin figures seen. They have also been described in red cells of patients with various abnormalities in erythropoiesis and after splenectomy (Kent et al., 1966). These authors suggested that the vacuoles result from engulfment by lysosomes of organelles or material no longer required by the cells, especially in the final stages of erythroid differentiation. We consider that the cytoplasmic structures seen in the patient's erythroblasts represent similar efforts in the disposal of redundant material, possibly including degraded nuclear membrane. If this is the case, the abnormality is present at the earliest recognisable stage of erythropoiesis, since vacuoles are seen in the proerythroblasts.

The fate of the myelin figure could either be engulfment and digestion by lysosomes or extrusion in a similar fashion to the normal normoblast nucleus. In both CDA types I and II the morphological abnormalities have been seen no earlier than the intermediate normoblasts; the changes in the proerythroblasts could therefore be interpreted as reflecting either a new form of CDA or a more severe form of one of these recognised types. The patient described, however, has a mild anaemia, which does not support the concept of a more severe form. We feel it does not fit into the categories of types II or III as both have definitive criteria for diagnosis, viz., positive acidified serum lysis test in type II and multinucleate gigantoblasts in type III.

At present type I has less reliable criteria, for: example, megaloblastoid maturation and internuclear bridging, which may be found to a lesser extent in acquired disorders of dyserythropoiesis. Because of this, we feel that this case should be considered as a type I variant rather than a separate category.

\section{References}

Bethlenfalvay, N. C. (1974). Letter to the editor. Blood, 43, 155.

Crookston, J. H., Crookston, M. C., Burnie, K. L., Francombe, W. H., Dacie, J. V., Davis, J. A., and Lewis, S. M. (1969). Hereditary erythroblastic multinuclearity associated with a positive acidified-serum test: a type of congenital dyserythropoietic anaemia. British Journal of Haematology, 17, 11-26.

David, G., and van Dorpe, A. (1977). Aberrant congenital dyserythropoietic anaemias. In Dyserythropoiesis, edited by S. M. Lewis and R. L. Verwilghen, pp. 93-100. Academic Press, London.

Dvilansky, A., Sukenik, S., Stern, J., and Djaldetti, M. (1974). Congenital dyserythropoietic anemia with ultrastructure findings compatible with both types I and II. Acta Haematologica, 52, 161-168.

Heimpel, H., Forteza-Vila, J., Queisser, W., and Spiertz, E. (1971). Electron and light microscopic study of the erythroblasts of patients with congenital dyserythro- 
poietic anemia. Blood, 37, 299-310.

Heimpel, H., and Wendt, F. (1968). Congenital dyserythropoietic anaemia with karyorrhexis and multinuclearity of erythroblasts. Helvetica Medica Acta, 34, 103-115.

Hruby, M. A., Mason, R. G., and Honig, G. R. (1973). Unbalanced globin chain synthesis in congenital dyserythropoietic anemia. Blood, 42, 843-850.

Kent, G., Minick, O. T., Volini, F. I., and Orfei, E. (1966). Autophagic vacuoles in human red cells. American Journal of Pathology, 48, 831-857.

Lewis, S. M., and Frisch, B. (1976). Congenital dyserythropoietic anaemias: electron microscopy. In Congenital Disorders of Erythropoiesis (Ciba Foundation Symposia, new series, 37), edited by R. Porter and D. W. Fitzsimons, pp. 171-203. Elsevier, Amsterdam.

Lewis, S. M., Nelson, D. A., and Pitcher, C. S. (1972). Clinical and ultrastructural aspects of congenital dyserythropoietic anaemia type I. British Journal of Haematology, 23, 113-119.

Lewis, S. M., and Verwilghen, R. L. (1972). Dyserythropoiesis and dyserythropoietic anaemia. British Journal of Haematology, 23, 1-4.

McBride, J. A., Wilson, W. E. C., and Baillie, N. (1971). Congenital dyserythropoietic anaemia-type IV (Ab- stract). Blood, 38, 837.

Maldonado, J. E., and Taswell, H. F. (1974). Type I dyserythropoietic anemia in an elderly patient. Blood, 44, 495-500.

Verwilghen, R. L., Lewis, S. M., Dacie, J. V., Crookston, J. H., and Crookston, M. C. (1973). HEMPAS: Congenital dyserythropoietic anaemia (type II). Quarterly Journal of Medicine, 42, 257-278.

Weatherall, D. J., Clegg, J., Knox-Macaulay, H. H. M., Bunch, C., Hopkins, C. R., and Temperley, I. J. (1973). A genetically determined disorder with features both of thalassaemia and congenital dyserythropoietic anaemia. British Journal of Haematology, 24, 681-702.

Weatherly, T. L., Flannery, E. P., Doyle, W. F., Shohet, S. B., and Garratty, G. (1974). Congenital dyserythropoietic anemia (CDA) with increased red cell lipids. American Journal of Medicine, 57, 912-919.

Wong, K. Y., Hug, G., and Lampkin, B. C. (1972). Congenital dyserythropoietic anemia type II: ultrastructural and radioautographic studies of blood and bone marrow. Blood, 39, 23-30.

Requests for reprints to: Dr M. W. Kenny, Central Pathology Laboratory, Hartshill Road, Hartshill, Stoke-on-Trent. 